\title{
Multiple Cracking Model of Fiber Reinforced High Performance Cementitious Composites under Uniaxial Tension
}

\author{
Xiangguo $\mathrm{Wu}^{1)}$ and Sang-Mook $\mathrm{Han}^{2)}$
}

(Received January 28, 2008, Revised June 30, 2008, Accepted June 30, 2008)

\begin{abstract}
A theoretical model of multiple cracking failure mechanism is proposed herein for fiber reinforced high performance Cementitious composites. By introducing partial debonding energy dissipation on non-first cracking plane and fiber reinforcing parameter, the failure mechanism model of multiple cracking is established based on the equilibrium assumption of total energy dissipation on the first crack plane and non-first cracking plane. Based on the assumption of the first crack to be the final failure crack, energy dissipation terms including complete debonding energy, partial debonding energy, strain energy of steel fiber, frictional energy, and matrix fracture energy have been modified and simplified. By comparing multiple cracking number and energy dissipations with experiment results of the reference's data, it indicates that this model can describe the multiple cracking behavior of fiber reinforced high performance cementitious composites and the influence of the partial debonding term on energy dissipation is significant. The model proposed may lay a foundation for the predictions of the first cracking capacity and post cracking capacity of fiber reinforced high performance cementitious composites and also can be a reference for optimal mixture for construction cost.
\end{abstract}

Keywords: cement, composites, multiple cracking, partial debonding, steel fiber

\section{Introduction}

Introduction of steel fibers in cementitious composites can stabilize microcracks in the matrix. Whenever microcracks are adequately suppressed from propagation, multiple cracking behavior may occur. Under uniaxial tension, fiber reinforced high performance cementitious composites (FRHPCC) exhibit multiple cracking and pseudo strain hardening behavior since the bridging fibers across the first crack and this bridging effects can be continuous as other microcracks are propagating. The major crack and other accompanied cracks can be noticed clearly in FRHPCC. Multiple cracking is one of the basic features for FRHPCC to get the pseudo strain hardening behavior.

Although there are some theoretical models to predict the improvement of multiple cracking of normal fiber reinforced concrete (FRC), the mechanism for improving the tensile strain capacity of FRHPCC is not well understood yet. The first attempt to define the conditions leading to multiple cracking of FRC was suggested by Naaman ${ }^{1}$ who suggested that the maximum postcracking stress in the composite under tension was larger than the stress at first cracking. The condition to achieve pseudo strain hardening and multiple cracking of FRC was also derived

\footnotetext{
${ }^{1)}$ School of Architecture Engineering, Harbin Engineering University, Harbin, 150001 China.

${ }^{2)}$ KCI Member, School of Civil Engineering, Kumoh National Institute of Technology, Gumi 730-701 Korea. E-mail: smhan@ kumoh.ac.kr

Copyright (c) 2009, Korea Concrete Institute. All rights reserved, including the making of copies without the written permission of the copyright proprietors.
}

using fracture mechanics concepts as developed by $\mathrm{Li}$ and $\mathrm{Wu},{ }^{2,3}$ and $\mathrm{Li}$ and Leung, ${ }^{4}$ and $\mathrm{Li}$, Stang, and Krenchel. ${ }^{5}$ Tjiptobroto and Hansen, developed a model based on fracture energy method to predict the strain at end of multiple cracking, and the critical volume fraction of fibers to guarantee the evolution of two cracks. ${ }^{6,7}$ Theoretically, the first crack should be the final major crack from energy dissipation and energy redistribution theory analysis. However, normally this is not true because of the influences of the test eccentricity and random imperfection. Tjiptobroto assumed that the first crack was the final failure major crack and the energy dissipated by other microcracks formation was the summation of the matrix fracture energy, fiber strain energy, and matrix strain energy. Identical assumption will be employed in this paper. In Tjiptobroto's assumption, however, there has no condition of debonding energy in multiple cracks. However, as the elastic strain is significantly increased in comparison with normal concrete and normal fiber concrete, the fiber-matrix interface is subjected to high interface stress particularly for high fiber modulus. The contribution of partial debonding energy in multiple cracking dissipation energy is significant and should not be neglected. Actually, there exists initial partial debonding and post cracking partial debonding along all the multiple cracks in FRHPCC.

A theoretical model of multiple cracking failure mechanism based on Tjiptobroto $^{8}$ is investigated herein to predict the multiple cracking behavior by energy dissipation. The model of effective fiber numbers in micro-unit body is adopted in the present study and fiber properties and orientation influences have been considered in the model. Multiple cracking occurs when the energy dissipations between the first crack and multi- 
ple cracks are in balance. By comparing the multiple cracking number prediction and energy dissipations with experimental data of Tjiptobroto, ${ }^{8}$ it indicates that the introduction of partial debonding energy term is necessary and the developed model can approximate the multiple cracking behavior of fiber reinforced composites. This model can also be a theoretical reference for optimal mixture of FRHPCC based on construction cost.

\section{Modified model of multiple cracking mechanism in FRHPCC}

\subsection{Energy change analysis during multiple cracking in FRHPCC}

Naaman and Shah $^{9}$ have proposed that an inelastic strain hardening region exists in FRHPCC. The region between the end of linear elastic range and the peak load denoted as region in Fig. 1 is a result of multiple micro cracking.

The linear elastic region, region I, denotes matrix microcracking stage. The softening stage, region III, corresponds to the single failure crack opening and is mainly controlled by the fiber pulling-out process. Regions I and II have been modeled for continuous aligned fiber composites by Aveston, Cooper, and Kelly, ${ }^{10}$ known as the ACK model, which is based on energy approach. Once a crack arises, the following energy changes can be assumed:

1) Full debonding energy $E_{d b}$ : to destroy the elastic interface bonding at the first cracking between the fiber and matrix.

2) Fiber strain energy $\Delta E_{f-m c}$ at the end of region II : the result of fiber bridging.

3) Frictional energy $\Delta E_{f r}$ : the work done against the frictional action along the displacement difference between fiber and matrix.

4) Matrix fracture energy $G_{m} V_{m}$ : the work done during new matrix crack formation.

5) Partial debonding energy $E_{p d b}$ : the energy dissipated between the stages of matrix fracture and fiber pulling-out.

The model proposed here considers the influence of partial debonding energy, and ignores the fiber strain energy and matrix strain energy at the end of point 1 because of the short steel fiber in FRHPCC. Fiber length can be classfied as short, medium and long by the interface failure mode of fiber pulling-out or

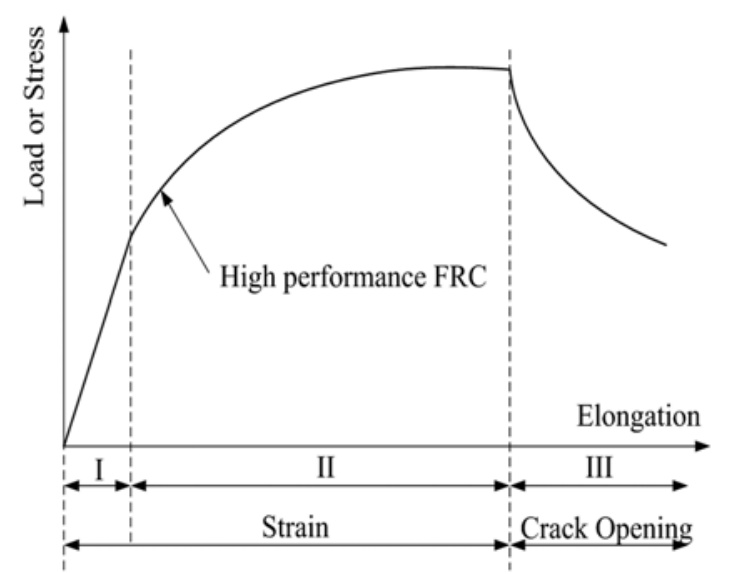

Fig. 1 Typical tensile load-elongation response for high performance FRC. $^{9}$ fracture. Evaluations of all the energy terms are simplified here. The partial debonding is assumed to exist on the interface of fiber and matrix at point 1 , while at point 2 it is assumed that the interface stress is a frictional stress distributed uniformly throughout the fiber embedment length. The assumption of partial debonding after first cracking is reasonable for the composites with high elastic modulus steel fiber.

\subsection{Energy terms $E_{1-2}$ and $E_{i 0}$}

As shown in Fig. 2, point 1 corresponds to the first crack (microcrack). Between point 1 and 2, this microcrack propagates and other cracks form simultaneously. The energy denoted as $E_{1-2}$ which is required to open the first crack from point 1 to point 2, i.e. the end of region II is the summation of complete debonding energy, fiber strain energy, and frictional energy as shown in Fig. 2.

$$
E_{1-2}=\Delta E_{f-m c}+\Delta E_{f r}+E_{d b}
$$

The energy required to form other cracks, denoted as $E_{20}, E_{30}$, $E_{40}, L, E_{n 0}$ is the summation of matrix fracture energy and partial debonding energy.

$$
E_{i 0} \approx G_{m} V_{m}+E_{p d b}(i=2,3, L, \mathrm{n})
$$

where, $G_{m}$ is the matrix fracture energy, and $V_{m}$ is the matrix volume fraction.

\subsection{Modified energy dissipation mechanism}

The basic concept of multiple cracking is that the energy dissipation $E_{1-2}$ for the first crack opening is larger than the energy dissipation summation $\sum E_{i 0}$ of other cracks.

If $E_{20}<E_{1-2}$, crack II forms with initial partial debonding and crack I continues to be debonded partially too. If $E_{20}+E_{30}<E_{1-2}$, crack III is formed with initial partial debonding, and crack II continues to be debonded partially, and crack I continues to be debonded partially too. On the analogy of this, when the conditions of $\sum_{i=2}^{n} E_{i 0} \leq E_{1-2}$ and $\sum_{i=2}^{n+1} E_{i 0}>E_{1-2}$ are satisfied simultaneously, the nth crack is formed with partial debonding, and the $(n-1)^{\text {th }}$ crack continues to be debonded partially, etc., crack II continues to be debonded partially, and crack I is completely debonded and enters into pull out stage, i.e. strain softening region III which is

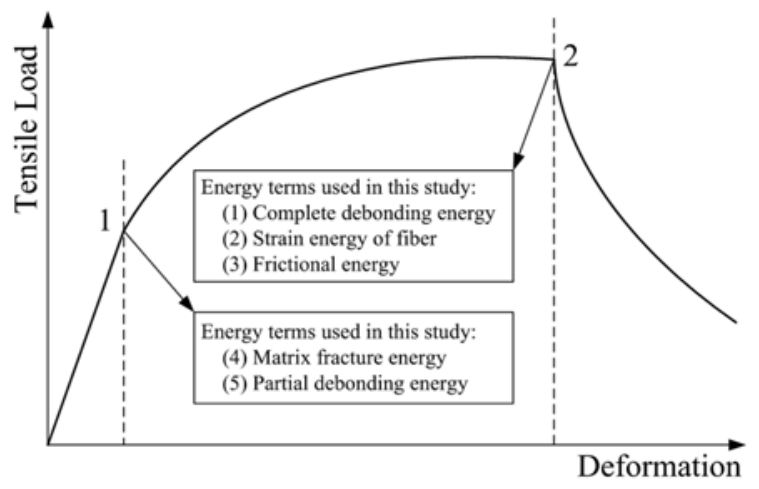

Fig. 2 Different energy terms considered in the modified model derivation. $^{10}$ 
corresponding to point 2 as shown in Fig. 2. From the view of statistics significance, debonding energy along every crack should be asymptotically reductive accumulation process and it will continue until the first crack is debonded completely. It is simplified as a constant partial debonding based on shear lag analysis.

The summation of partial debonding energy of non-first crack represents the total partial debonding energy. The initial debonding energy before matrix fracture is omitted here as compared with $E_{p d b}$. The total number of cracks is $n$ and the total energy dissipations approach to $E=E_{1-2}+\sum_{i=1}^{n} E_{i 0}$.

\section{Theoretical prediction of energy dissipation terms}

\subsection{Strain energy of steel fiber $\Delta E_{f-m c}$}

The total strain energy of steel fiber at the post cracking stage can be modified as

$$
\Delta E_{f-m c}=\frac{N_{f u}}{2 E_{f}} \int_{0}^{L_{f} / 4} \sigma_{f 2}^{2}(x) d x
$$

in which $\sigma_{f 2}$ is the fiber stress at the second stage. $N_{f i}$, the effective number of steel fiber in micro-unit $L_{f} \times L_{f}$, can be expressed as ${ }^{11}$

$$
N_{f u}=\frac{4 V_{f} L_{f}^{2}}{9 \pi D_{f}^{2}}
$$

By substituting Eq. (4) into Eq. (3), the strain energy of steel fiber can be obtained as

$$
\Delta E_{f-m c}=\frac{7 L_{f}}{24 E_{f}} \cdot \frac{4 V_{f} L_{f}^{2}}{9 \pi D_{f}^{2}} \cdot \frac{\tau_{f m}{ }^{2} L_{f}^{2}}{D_{f}^{2}}=\frac{7 V_{f} \tau_{f m}^{2} L_{f}^{5}}{54 \pi E_{f} D_{f}^{4}}
$$

in which, $L_{f}$ is steel fiber length, $D_{f}$ is steel fiber diameter, $E_{f}$ is the elastic modulus of steel fiber, $\tau_{f m}$ is the interfacial bonding strength, and $V_{f}$ and $V_{m}$ are the volume fraction of fiber and matrix, respectively.

\subsection{Frictional energy $\Delta E_{f r}$}

Frictional energy is the energy dissipated due to strain difference between fiber and matrix at the first crack.

$$
\begin{aligned}
& \Delta E_{f r-\text { perfiber }}=\pi D \int_{0}^{L_{f} / 4} \tau_{f m} \varepsilon_{f 2}(x) d x \\
& \Delta E_{f r-\text { total }}=N_{f u} \cdot \Delta E_{f r-\text { perfiber }}
\end{aligned}
$$

Then

$$
\Delta E_{f r-\text { total }}=\frac{4 V_{f} L_{f}^{2}}{9 \pi D_{f}^{2}} \cdot \frac{\pi \tau_{f m} D_{f} L_{f}^{2}}{16} \cdot \frac{2 \tau_{f m} L_{f}}{3 E_{f} D_{f}}=\frac{V_{f} D_{f} \tau_{f m}{ }^{2} L_{f}{ }^{5}}{216 E_{f} D_{f}^{2}}
$$

\subsection{Full debonding energy $E_{d b}$}

Full debonding energy is the term dissipated to destroy entire bonding between the fiber and matrix at the first crack.

$$
E_{d b}=N_{f u}\left(\pi D_{f} \cdot \frac{L_{f}}{4} \cdot G_{\mathrm{II}}\right)
$$

Then

$$
E_{d b}=\frac{V_{f} L_{f}^{3} G_{\mathrm{II}}}{9 D_{f}}
$$

where $G_{\mathrm{II}}$ is the fracture energy in shear fracture model.

\subsection{Partial debonding energy $E_{p d b}$}

Partial debonding energy is composed of two parts, i.e. at the stage of the first cracking and post cracking, and can be expressed approximately as

$$
E_{p d b}=\frac{4 L_{p d b}}{L_{f}} E_{d b}
$$

Derivation of partial debonding length $L_{p d b}$ based on shear lag theory is shown in Appendix.

\section{First cracking energy and general post cracking energy}

\subsection{First cracking energy dissipation}

The energy at the first cracking is composed of two parts, i.e. matrix contributions and steel fiber contributions.

$$
E_{\text {initial }}=E_{\text {matrix }}+E_{\text {fiber }} \cdot N_{u f}
$$

In which

$$
E_{\text {matrix }}=G_{m}\left(1-V_{f}\right)
$$

$$
E_{\text {fiber }}=G_{m}\left(\frac{E_{f}}{E_{m}}\right)
$$

Then

$$
E_{\text {initial }}=\gamma_{1} G_{m}\left(1-V_{f}+\frac{4 E_{f} L_{f}^{2}}{9 \pi E_{m} D_{f}^{2}} V_{f}\right)
$$

where $\gamma_{1}$ as a snubbing coefficient equals to 0.65 for FRHPCC.

\subsection{General energy dissipation of post cracking}

The total post cracking energy dissipation is composed of the energy dissipated resulted by the first major crack and other multiple cracks i.e.

$$
E=E_{1-2}+\sum_{i=1}^{n} E_{i 0}=2 \gamma_{2} E_{1-2}
$$

where $\gamma_{2}$ as a snubbing coefficient equals to 1.2 for FRHPCC. 


\section{Computation and comparative analysis}

\subsection{Critical fiber volume fraction and multiple cracking numbers}

According to the flow chart of the model shown in Fig. 3, the numerical calculation can be carried out here.

\subsection{Input parameters and flow chart of the numerical calculation}

The input parameters of FRHPCC based on Tjitobroto ${ }^{8}$ are shown in Table 1. The interface shear fracture energy is assumed to be equal to matrix fracture energy approximately since it is difficult to be determined. Fiber interface friction stress can be measured by fiber pulling-out experiment. The measurement of matrix fracture energy can be obtained from matrix fracture experiments. $^{12}$

\subsection{Test results of Tjiptobroto}

Tjiptobroto ${ }^{8}$ carried out the test with specimen dimension $50 \mathrm{~mm} \times 50 \mathrm{~mm} \times 500 \mathrm{~mm}$ and span length $420 \mathrm{~mm}$ loaded by two points loading manner. The specimen and test results are shown in Fig. 4.

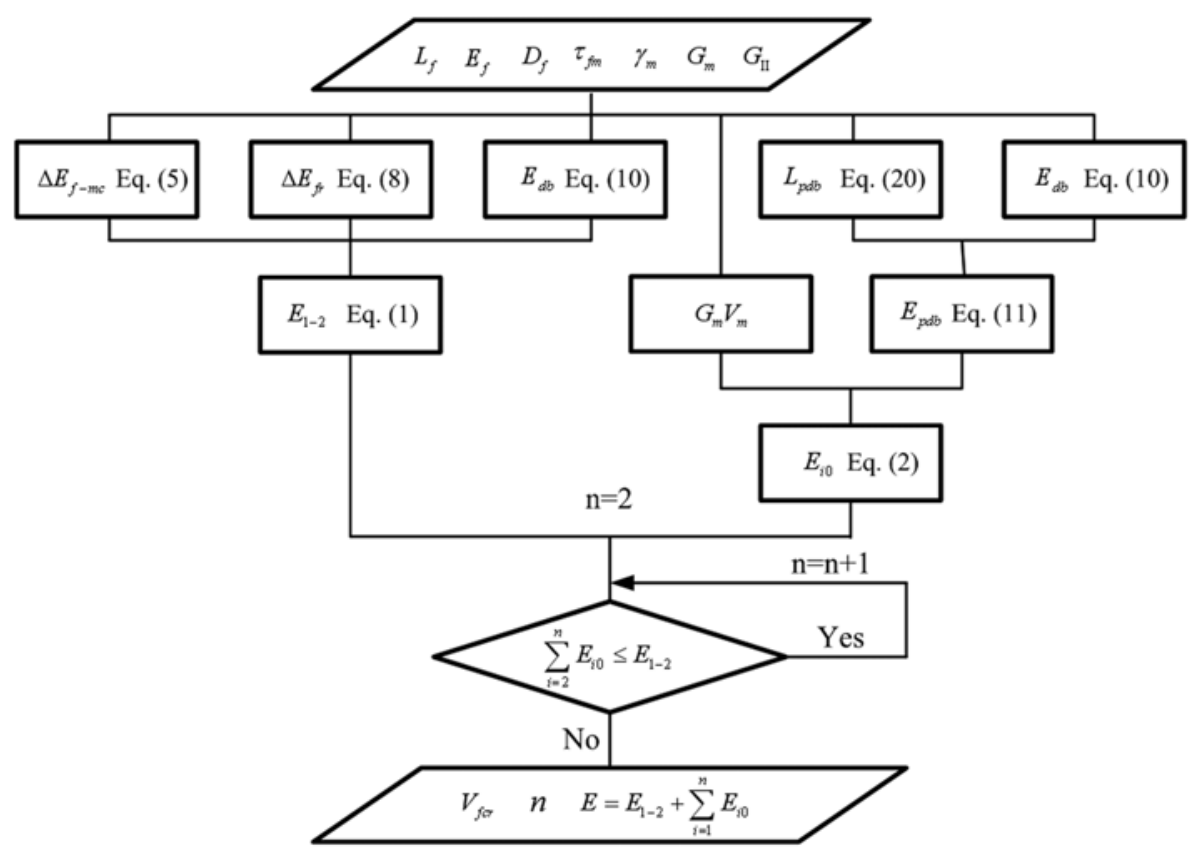

Fig. 3 Flow chart of computation.

Table 1 The input data of FRHPCC. ${ }^{8}$

\begin{tabular}{l|c|l|c}
\hline \multicolumn{1}{c|}{ Matrix } & \multicolumn{2}{c}{ Steel fiber } \\
\hline \hline Fracture energy, $G_{m}\left(\mathrm{~N} \cdot \mathrm{m}^{-1}\right)$ & 120 & Modulus of elasticity $E_{f}(\mathrm{MPa})$ & 200,000 \\
\hline Frictional stress, $\tau_{f m}(\mathrm{MPa})$ & 10 & Length $L_{f}(\mathrm{~mm})$ & 6 \\
\hline Interface fracture energy, $G_{\mathrm{II}}\left(\mathrm{N} \cdot \mathrm{m}^{-1}\right)$ & 120 & Diameter $D_{f}(\mathrm{~mm})$ & 0.15 \\
\hline Modulus of elasticity, $E_{m}(\mathrm{MPa})$ & 49100 & & \\
\hline
\end{tabular}

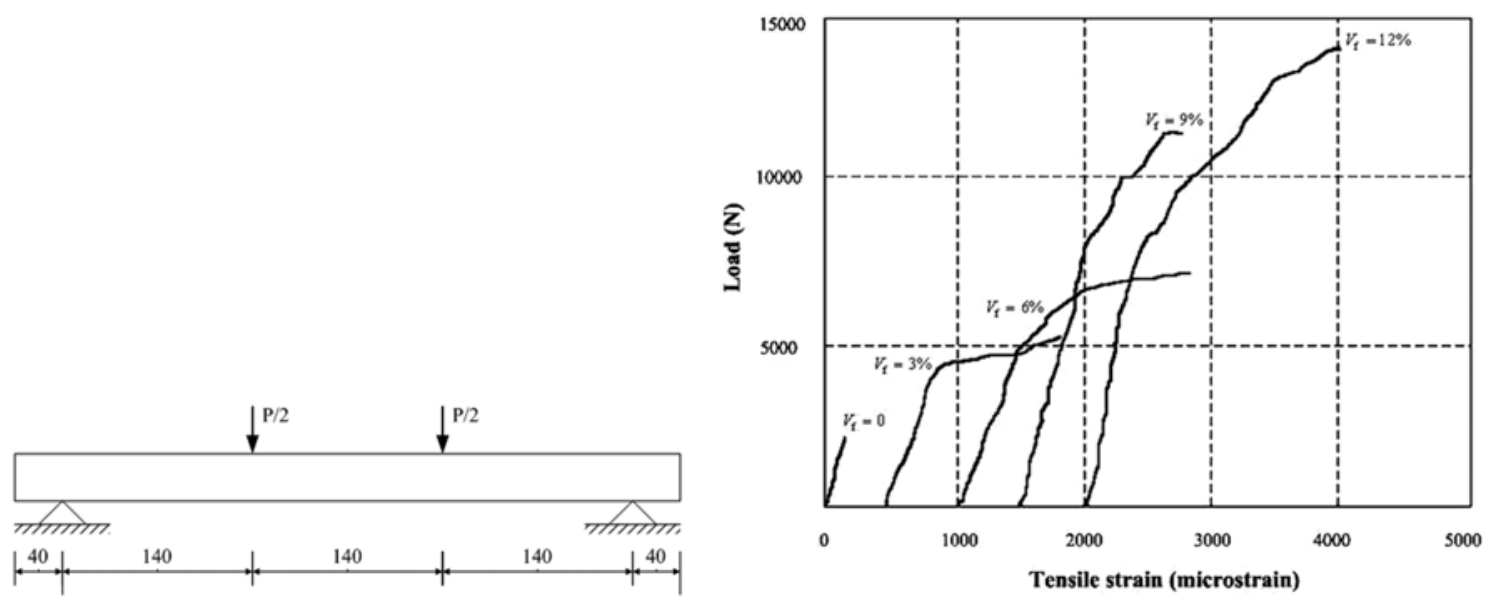

Fig. 4 Test specimen and results of Tjiptobroto. ${ }^{8}$ 


\subsection{Calculation and comparison with the test results from references}

Multiple cracking numbers with fiber volume fraction are shown in Fig. 5. It can be seen that the energy dissipation and multiple cracking numbers increase with the increasing of the fiber volume fraction. Tensile failure occurs once the energy dissipation at the first cracking is balanced with other multiple cracks. Comparison between the predictions and the test results of Tjiptobroto ${ }^{8}$ is also shown in Figs. 5 and 6.

The predictive result of initial energy dissipation at first cracking is shown in Fig. 7(a) and the initial energy dissipation with different fiber volume fraction can be predicted. The corresponding test results are also shown in Fig. 7(a). The numerical predictions agree with the experimental results well. The predictive results of the total energy dissipation at post cracking with partial debonding energy are shown in Fig. 7(b), in which the solid line represents the energy with partial debonding term and the dashed line represents the energy without partial debonding term. The corresponding test result is also shown in Fig. 7(b). The numerical results with partial debonding term show good agreement with the test results.

\section{Conclusions}

1) Based on energy dissipation criterion, this paper carried out the research on multiple cracking propagation mechanism for FRHPCC. This model predicts that the number of multiple cracks depends on the fiber volume fraction and fiber properties.

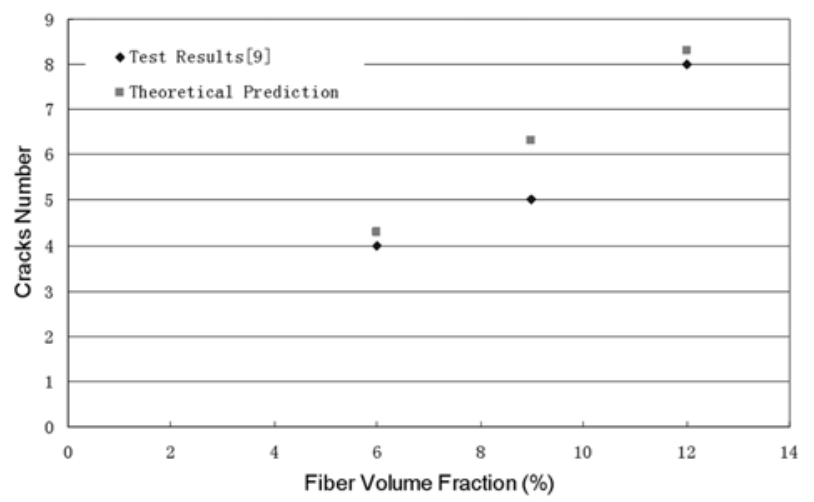

Fig. 6 Crack number comparison between test results and theoretical prediction.

Critical fiber volume fraction can be obtained when cracks number, i.e. multiple cracking degrees, and fiber properties are all known. This will provide a theoretical reference for optimal mixture design of FRHPCC and for the construction cost optimization.

2) Partial debonding energy and introducing of the effective fiber numbers on micro-unit are reasonable from the comparison of other multiple cracks' energy dissipation with the test results. The snubbing coefficients considering the model error are relatively reasonable. To change the snubbing coefficients, this model can be transformed into a new model for other type fiber reinforcing composites.

3) The influence of partial debonding term on post cracking

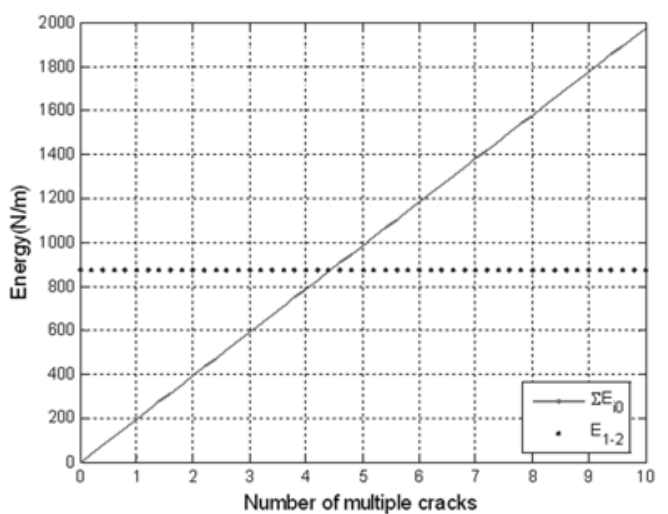

(a) $V_{f}=6 \%, L_{f}=6 \mathrm{~mm}, D_{f}=0.15 \mathrm{~mm}$

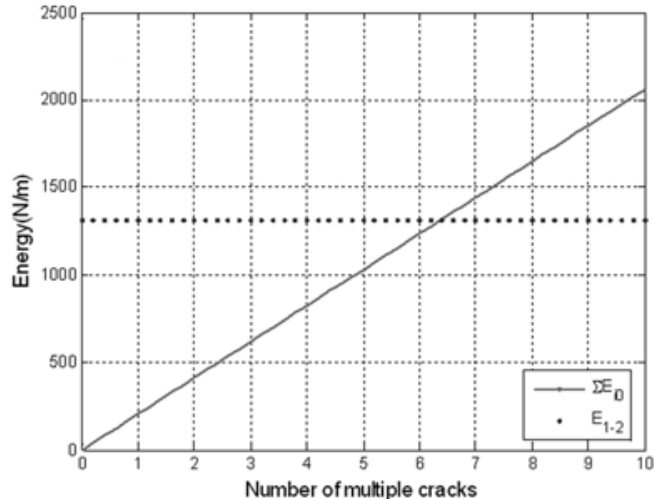

(b) $V_{f}=9 \%, L_{f}=6 \mathrm{~mm}, D_{f}=0.15 \mathrm{~mm}$

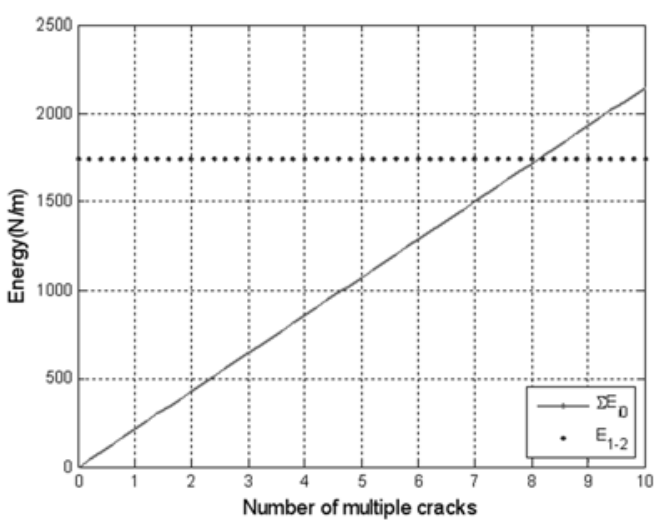

(c) $V_{f}=12 \%, L_{f}=6 \mathrm{~mm}, D_{f}=0.15 \mathrm{~mm}$

Fig. 5 Variation of energy $E_{1-2}$ and $\Sigma E_{i 0}$ vs number of cracks. 


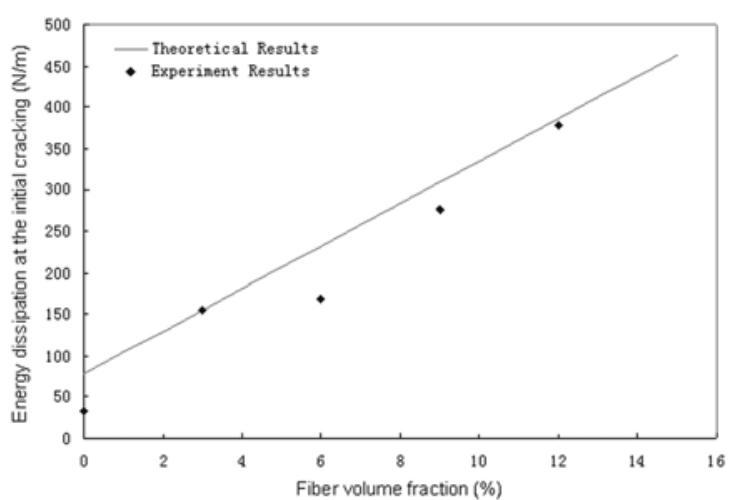

(a) First cracking

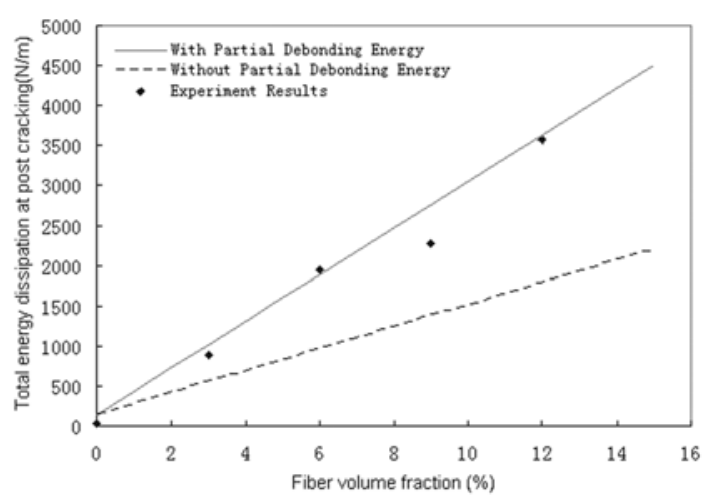

(b) Post cracking

Fig. 7 Variation of energy dissipation vs fiber volume fraction.

dissipation energy is significant and the difference compared with that without partial debonding is about $20 \sim 30 \%$. Both the initial energy dissipation predictions and the total energy dissipations with partial debonding term show good agreements with the test results. The former can be used to predict the first cracking loading capacity and the initial constitutive relation at end of the first cracking stage. The latter can be used to predict the post cracking loading capacity.

\section{Acknowledgments}

This paper was one part of the research subject "Development and Application of High Performance and Multi-Function Concrete" which has been accomplished now. The authors gratefully acknowledge the financial support of "Center of Concrete Corea, Korea."

\section{References}

1. Naaman, A. E., "High Performance Fiber Reinforced Cement Composites," Concrete Structure for the Future, IABSE Symposium, Paris-Versailles, 1987, pp. 371 376.

2. Li, V. C. and Wu, H. C., "Conditions for Pseudo StrainHardening in Fiber Reinforced Brittle Matrix Composites," $J$. Applied Mechanics Review, Vol. 45, No. 8, 1992, pp. 390 398.

3. Li, V. C., "Post-Crack Scaling Relations for Fiber Reinforced Cementitious Composites," ASCE J. of Materials in Civil Engineering, Vol. 4, No. 1, 1992, pp. 41 57.

4. Li, V. C. and Leung, C. K. Y., "Theory of Steady State and Multiple Cracking of Random Discontinuous Fiber Reinforced Brittle Matrix Composites," ASCE J. of Engineering Mechanics, Vol. 118, No. 11, 1992, pp. 2246 2264.

5. Li, V. C., Stang, H., and Krenchel, H., "Micromechanics of Crack Bridging in Fiber Reinforced Concrete," J. of Materials and Structures, Vol. 26, 1993, pp. 486 494.

6. Tjiptobroto, P. and Hansen, W., "Tensile Strain Hardening and Multiple Cracking in High-Performance Cement Based Composites Containing Discontinuous Fibers," ACI Materials Journal, Vol. 90, No. 1, 1993.

7. Tjiptobroto, P. and Hansen, W., "Model for Predicting the Elastic Strain of Frc Containing High Volume Fractions of Discontinuous Fibers," ACI Materials Journal, Vol. 90, No. 2, 1993.

8. Tjiptobroto, P., "Tensile Strain Hardening of High Per- formance Fiber Reinforced Cement-Based Composites," PhD dissertation, University of Michigan, Ann Arbor, 1991, 209 pp.

9. Naaman, A. E. and Shah, S. P., "Fracture and Multiple Cracking of Cementitious Composites," Fracture Mechanics Applied to Brittle Materials, Proceedings of the $11^{\text {th }}$ National Symposium on Fracture Mechanics, Smith, C. W. and Freiman, S. W. eds., ASTM, 1979, pp. 183 201.

10. Aveston, J., Cooper, G. A., and Kelly, A., "Single and Multiple Fracture. The Properties of Fibre Composites," Conference Proceedings of National Physical Laboratory, IPC Science and Technology Press Ltd., 1971, pp. 15 24.

11. Wu, X. G.., Han, S. M., Kim, S. W., and Kang, S. T., "Shear Failure Load of SFR-UHPCCC I-Beam without Stirrup Based on Limit Analysis of Concrete Plasticity," Proceedings of the International Conference on Fracture and Damage Mechanics V, Key Engineering Materials, Vol. 324, 2006, pp. 491 494.

12. Shah, S. P., Swartz, S. E., and Ouyang, C. S., Fracture Mechanics of Concrete: Applications of Fracture Mechanics to Concrete, Rock and Other Quasi-Brittle Materials[M]. A WileyInterscience Publication, 1995, pp. 162 175.

\section{Appendix}

The partial debonding length after cracking $L_{p d b}$ can be calculated using the following expression for interfacial stress developed based on the shear-lag theory. ${ }^{8}$

$$
\begin{aligned}
& \tau_{\text {elastic }}(x)= \\
& \frac{1}{2} \Phi \alpha E_{f} \varepsilon_{m u}\left[\frac{2 \cosh \left(\Phi L_{f} / D_{f}\right)-1}{2 \sinh \left(\Phi L_{f} / D_{f}\right)} \cosh \left(\frac{2 \Phi x}{D_{f}}\right)-\sinh \left(\frac{2 \Phi x}{D_{f}}\right)\right]
\end{aligned}
$$

in which

$$
\Phi=\sqrt{\frac{E_{m}}{E_{f}\left(1+v_{m}\right) \ln \left(2 R / D_{f}\right)}}
$$

where $\varepsilon_{m u}$ is the elastic strain which can be expressed as

$$
\varepsilon_{m u}=\sqrt{\frac{2 \gamma_{m} V_{m}}{\left[3 E_{c} / 4-7 E_{f} V_{f}(1+\alpha) / 24\right] \alpha L_{f}}}
$$


where $\gamma_{m}$ is the surface energy and equals to $G_{m} / 2$, and composite modulus of elasticity $E_{c}$ including its parameters can be calculated from

$$
\frac{1}{E_{c}}=0.5\left(\frac{1}{E_{c l}}+\frac{1}{E_{c u}}\right)
$$

$E_{c l}$ and $E_{c u}$ are the lower limit and the upper limit and given by

$$
\begin{aligned}
& E_{c l}=\frac{1}{\frac{1-V_{f}}{E_{m}}+\frac{V_{f}}{E_{f}}} \\
& E_{c u}=E_{m}\left(1-V_{f}\right)+E_{f} V_{f}
\end{aligned}
$$

$$
\alpha=\frac{E_{m} V_{m}}{E_{f} V_{f}}
$$

$V_{m}$ is the Poisson's ratio of the FRHPCC matrix, and

$$
R=\frac{D_{f}}{4} \sqrt{\frac{\pi}{V_{f}}}
$$

Now, let

$$
\left[\tau_{\text {elastic }}(x)\right]_{\max }=\tau_{f m}
$$

$L_{p d b}$ can be obtained from Eq. (20), and so the partial debonding energy $E_{p d b}$. 